\title{
Cultural Supervision and Cultural Competence in the Practice of Psychotherapy and Applied Psychology
}

\author{
Margaret Poutu Morice (Ngati Porou) \\ and Jonathan Fay
}

ONGA ONGA, HAWKE'S BAY AND AUCKLAND

\begin{abstract}
The article offers an overview or meta-perspective on the parallels and kinship between cultural supervision and clinical supervision and between cultural supervision and cultural competence. It discusses some cultural competencies specific to working with indigenous Māori, competencies which may also establish principles of cultural competency for working safely and effectively amongst multiple lived realities within multicultural societies. It compares and contrasts aspirational and regulatory approaches to cultural competence and suggests some ways in which cultural competencies might be measureable and measured. Finally, it links the practice of cultural supervision to the development and maintenance of cultural competence.
\end{abstract}

\section{Whakarāpopoto}

He whakatakororanga whakaaro whānui tā tēnei tuhinga whakakapā atu ki te heretangata me ngā hono o te ahurea kaiwhakahaere me te ahurea kaitaunaki me te ahurea matatau. Ka matapakihia ètahi ahurea matatau arotika atu ki te mahi i te taha o te Māori, ngā mātauranga tērā pea ka whakaū mātāpono tūāpapa pūkenga mō te ora te mana i waenga i te rahi i te ahurea-tini porihanga. Ka whakaritea ka whakarerekēhia ngā moemoeā ngā momo whai i te koeke ahurea â, ka whakaarahia ètahi huarahi e kitea ai te inetanga, te whakaineahurea koeke.Hai te mutunga,ka honoa the whakawai o te ahurea kaiwhakahaere ki te whanaketanga me te pupuritanga o te ahurea matatau.

Key words: cultural supervision; cultural competence; psychotherapy; applied psychology, cultural safety; cultural awareness; cultural sensitivity; cultural humility; bicultural; biculturalism

Morice, M. P., \& Fay, J. (2013). Cultural supervision and cultural competence in the practice of psychotherapy and applied psychology. Ata: Journal of Psychotherapy Aotearoa New Zealand, 17(1), 89-101. DOI: 10.9791/ajpanz.2013.07 () New Zealand Association of Psychotherapists Inc. 


\section{Introduction}

The working assumption of our approach to cultural supervision and cultural competence is that individual psychology and culture co-exist and co-determine each other. Culture is the public face of psyche and psyche the private face of culture. Culture is the aggregate of individual psychologies within a particular reference group, but it is also the matrix in which individual identity is formed via socialisation and the context in which human beings reaffirm and renew their group memberships. Individual psychology is itself a "microculture" that mirrors and contributes to the larger culture of the family, group, and community (Fay, 2008, 2011). Both individual psychology and culture are largely unconscious, reliant upon implicit rather than explicit memory, operating from unconscious frames of reference that are woven into the very fabric of the language and customs we make use of to understand and express ourselves (Dalal, 2002).

Cultural supervision claims the same kinship with clinical supervision that culture claims with individual psychology. Clinical supervision brings into focus the psychology of individual human beings, but every person is the final common pathway of a complex confluence of diverse cultural influences (Rich, 1993). Considered from a clinical perspective, our private identity is our own unique microculture, our personal synthesis of all the roles we inhabit and all the cultures to which we belong. Cultural supervision explores the relationship between individual psychology and all of the reference groups that help to form it (Morice \& Fay, 2012).

Psychotherapeutic competence is the ability to help people differentiate and integrate the diverse influences in their lives and histories, to develop their autonomy and independence from the matrix of their reference groups, but also to develop their interdependence, to affirm and deepen their connections to the members of those groups. The ability of the psychotherapy practitioner to be of service depends upon the empathic capacity to stand in the shoes of the Other, to recognise and understand their positionality and their perspective (Fuertes, 2004). Cultural competence is, therefore an essential ingredient of good clinical work, and cultural supervision a valuable form of assistance to this end (Durie, 2001; McKinney, 2006). Cultural supervision does not require exotic identities as its subject matter. It is applicable to all people everywhere, equally relevant when therapist and client come from the same reference group as when they do not. It is antithetical to the work of psychotherapy to suppose that only differences are worth discussing or that being the same brings perfect understanding (Vera \& Speight, 2003).

Cultural supervision and clinical supervision share many similarities:

1. Each makes explicit the dialectic of action and reflection and requires a high level of reflexive self-awareness.

2. Each seeks to reduce risk and ensure safety for therapists, their clients, and the community at large.

3. Each assists with the development and maintenance of competent practice.

Our skills and abilities as effective practitioners are both extended and enhanced by our ability to understand and reflect on the cultural dimensions of our work with clients (Morice \& Fay, 2012). 
To date, the Psychotherapy Board of Aotearoa New Zealand (PBANZ) has held and holds the position that any psychotherapy practitioner familiar with the Aotearoa New Zealand context will automatically possess the requisite cultural competency for safe and effective practice. Only practitioners deemed fit for registration but who are also recent arrivals to New Zealand may be asked by PBANZ to provide evidence of competence to practice in the New Zealand context. This is expressed in its statement on Competence to Practice in the New Zealand Context:

Within 12 months a practitioner with this condition on their scope will provide the Board with evidence that they are competent in the following areas: Te Tiriti o Waitangi and relevance to psychotherapy practice in bicultural NZ; Cultural and social dynamics and safety specifically relevant to bicultural NZ; Understanding of the New Zealand Health sector and New the Zealand [sic] law relevant to psychotherapy practice. (PBANZ, 2013)

By contrast, the New Zealand Psychologists' Board (NZPB) offers a much clearer and more focused guideline to culturally competent practice which includes all practitioners and not just newcomers:

Cultural competence is defined as having the awareness, knowledge, and skills, necessary to perform a myriad of psychological tasks that recognises the diverse worldviews and practices of oneself and of clients from different backgrounds. Competence is focused on the understanding of self as a culture bearer; the historical, social and political influences on health ... and the development of relationships that engender trust and respect. Cultural competence includes an informed appreciation of the cultural basis of psychological theories, models and practices and a commitment to modify practice accordingly. (NZPB, 2011, p. 4)

A critical component of developing cultural competence is the recognition of the limits and boundaries to our own experience and expertise: knowing what we do not know is cruical (Wear, 2003). It has even been suggested that "cultural humility" might be a more appropriate term than cultural competence (Tervalon \& Murray-Garcia, 1998). This is because it is precisely our own life experience, our positionality and our perspective from this position which blinds us to dissimilarity and difference in the life experience of other people. Cultural competence is, therefore, not so much a goal to be achieved as a process of life-long learning which consists of an ongoing series of engagements with others across the cultural interface (Jones, 1999; Morice, 2006). Acknowledging the limits of our knowing and the profound mystery of all that remains unknown is essential to the development of wisdom in the practice of psychotherapy (Fay, 2007).However, both clinical and cultural competence also involves the development of certain positive attributes, attitudes and specific types of awareness, knowledge, skills and practices (Morice, 2003).

Durie (2001) has described cultural competence as "the acquisition of skills to achieve a better understanding of members of other cultures” (p. 4). Other indigenous Māori 
educators such as Ranginui Walker in Ka Whawhai Tonu Matou (1990) and Linda Tuhiwai Smith in Decolonising Methodologies (1999) have suggested that it is not only the inclusion of cultural content but the integration of indigenous pedagogy which may be crucial to the development of cultural competence. Indigenous pedagogy refers to a set of conceptual tools: cultural values, protocols, and practices which provide a frame of reference that rules some things in as important or relevant and other things out as less important or less relevant. Mãori models of practice which can help to provide these conceptual tools include Te Whare Tapa Wha (Durie, 1985), Te Wheke (Pere, 1988), and Te Taiao/Te Ao Marama (McKinney, 2006).

This article does not offer an additional model of practice, but rather an overview, a meta-perspective on the work of cultural supervision and the development of cultural competence. Firstly, we discuss some cultural competencies specific to working with indigenous Māori.

\section{Cultural Supervision and Cultural Competence in the Practice of Psychotherapy}

There are at least three ways in which cultural supervision might contribute to the competent practice of psychotherapy in Aotearoa New Zealand:

1. To enhance competent practice with Mãori clients

2. To enhance accurate understanding and enjoyment of this unique land

3. To enhance competent practice with the full spectrum of culturally diverse clients encountered in the Aotearoa New Zealand context.

\section{Working with Māori clients}

The history and heritage of Aotearoa New Zealand is bicultural. As the original and only inhabitants of Aotearoa for many hundreds of years, Māori took and continue to take their host responsibilities very seriously. The cultural obligation to offer hospitality and to be inclusive runs very deep within traditional Māori culture (Morice, 2003, 2012). British visitors and immigrants were initially welcomed as honoured guests; however, Pākehā (fair-skinned ones) and Tau Iwi (people not born in NZ, visitors, foreigners) brought with them a very different attitude: a mindset of cultural superiority and the determination and technology to enforce this mindset. Today, in the wake of colonisation, Māori are heavily penalised and disadvantaged in a myriad of ways simply for being Māori, and continue to be regarded as and treated as the racialised Other by the European majority, sometimes idealised, but more often devalued (Morice 2003; Walker, Eketone, \& Gibbs, 2006). White New Zealanders can choose whether and how much they wish to engage with Te Ao Mãori (the Māori world). Māori, however, do not have this same choice, but are compelled to live in a "mainstream" white, Western world (Morice, 2006). All Māori live in two worlds; all Māori organisations and endeavours straddle two worlds. Some Māori navigate elegantly and successfully between these two worlds; many others do not. To be Māori is to be linked by whakapapa or genealogy to all other Māori; however, Māori people comprise a very broad range of life experiences and a diversity of personal and cultural identities. 
When working with a Māori client, it is unwise to assume the client's familiarity with Te Ao Māori or to assume any particular attitude towards the Māori world. Clients may love or hate themselves for being Māori; they may love or hate others for being Māori; they may not know how they feel. They may experience ambivalence, uncertainty, confusion, and insecurity. They may envy or admire the Pākehā world for its confident assertions of power, privilege, and cultural validity. They may or may not look for support from mainstream sources. They may fear their dependency, resent their need, or simply be asking for reciprocity and interdependence. Neglecting the relationship between a Māori client and Te Ao Māori can be at least as harmful as making incorrect or naïve assumptions. Whenever the therapist allows him or herself to be mistaken, the client is given an opportunity to correct these mistakes and to offer another view. Ignoring cultural identity issues in therapy may contribute to cultural repression and oppression (Gone, 2010).

\section{Developing a personal relationship with Te Ao Māori}

This can be a life-long challenge and opportunity for Māori and non Māori alike. Most psychotherapy practitioners believe that the struggle of individual Māori clients to develop a healthy identity has meaning and value. Many such practitioners also believe that the collective Māori struggle for survival and the preservation of their unique cultural identity has meaning and value as well. Survival and self-preservation, equity and justice, protection, participation, partnership, and the historical saga of loss and grief, mourning and reparation, are all issues that are very important but by no means exclusive to Māori. Many Pākehā and Tau Iwi psychotherapy practitioners tend to stand at a distance from the "mainstream" and will or can resonate to these same issues and concerns. Where there is positive resolution of these concerns, good health and full participation in society flourish. Many Pākehā and Tau Iwi therapists also find affinity with the Mãori orientation to spirituality, with its emphasis on belonging, membership and interdependence, and its deep appreciation of the natural world which nourishes and sustains all life. Studying Te Reo Māori and learning about Tikanga Māori can become a pathway to understanding Te Ao Māori and deepening appreciation for indigenous, non Western perspectives on creation and life. When attempting to develop "soul" in Aotearoa New Zealand, it makes sense to seek some significant encounter with Māori traditions, Māori beliefs, and Māori people.

\section{Working with diversity in Aotearoa New Zealand}

In order to achieve anything like a genuinely multicultural society in the unique social, political, and cultural context that is Aotearoa New Zealand, it will be necessary to honour Te Tiriti o Waitangi | the Treaty of Waitangi and to engage in a sustained and ongoing process of decolonisation and bicultural power-sharing (Morice \& Woodard, 2011). The restoration of parity between Māori and Pakeha, between an indigenous people who have been marginalised in their own land and the descendants of their colonial rulers, is a far from easy task; it is, however, precisely this work which can set the stage for a positive affirmation of difference and diversity across all sectors of society which is more than skin deep. Ivey, Ivey and Simek-Morgan's (1993) multicultural or (interestingly) 
"respectful" cube usefully illustrates progress along these lines in three dimensions of difference in multicultural work;

- Nine specific multicultural issues (or dimensions of difference), i.e., language, gender, ethnicity, religion, sexual orientation, age, physical issues, socio-economic status, and trauma

- Four developmental stages of cultural identity development, from acceptance through naming/resistance, and reflection/redefinition, to multiperspective internalisation

- Five contextual variables of locations in or levels on which these concerns and developments might occur, i.e., the individual, family, group, community, and country.

Individual psychodynamics are a reflection and microcosm of family dynamics, and family dynamics are a reflection and microcosm of wider social and cultural forces (Fay, 2008, 2011, 2012). Many clients struggle to find a safe place in their families of origin. Many families are members of groups and communities that struggle to find a safe place in society. Clients who identify as mainstream are often deeply unconscious of their multi-generational family histories, unaware of the degree to which these histories have contributed to shaping their personality and personal functioning. Just as the privileges and prerogatives of being male may be much more clearly visible and obvious to women than to men, so the privileges and prerogatives of being white may be much more clearly visible and obvious to non whites than to whites (McIntosh, 1990). In Aotearoa New Zealand, many Pākehā clients have inherited and carry within themselves the legacy of multi-generational colonising influences and attitudes, as well as other influences and attitudes that run counter to and oppose this dominant narrative. Within the framework of the dominant white, Western status quo, these attitudes and their historical origins may remain quite invisible and unconscious. The situation is somewhat different for Tau Iwi clients, particularly non white Tau Iwi clients. The experience of being an immigrant and a newcomer or cultural outsider, especially if your skin is dark, is negotiated on the grounds and terms of the dominant culture. It is the dominant culture that offers "safety" and tolerance, but usually on its own terms. Power is not easily or often shared voluntarily.

\section{Aspirational and Regulatory Approaches to Cultural Supervision and Cultural Competence}

Aspirational approaches to cultural competence hope for much and ask much (Morice \& Fay, 2012). They seek to recognise and appreciate the unexpected gifts of the intercultural encounter and to identify persons and relationships that have the potential to become sources of guidance and inspiration. They look to cultural supervision to widen the scope of our imaginative capacities and transform our attitudes towards the Other and otherness. They seek to expand our consciousness to the alpha and omega of birth and death and beyond; to expand our empathy to all people in all places and times and beyond; to include the non human species with whom we share the Earth; and to include 
Nature and the Cosmos itself: a Universe bound together by whakapapa, in which all things and all processes are recognised as intimately related and interconnected, which makes room for physics, but also honors metaphysics. Psychotherapy practitioners are committed to the principle that the inner and the outer world are wider and deeper than we could ever know. Aspirational approaches to cultural supervision and cultural competence such as those espoused by NZAP and its Treaty Partner Waka Oranga seek to put this principle into practice (Morice \& Hall, 2011; Morice \& Fay, 2012).

Regulatory approaches to cultural competence do not ask for the stars, but only that we not do harm. Regulatory approaches sacrifice scope in order to gain precision. This agenda may be driven by government statutory requirements, prescribed professional codes of conduct, or voluntary approaches such as co-regulation or self-regulation. In Aotearoa New Zealand, all of the relevant state regulatory responsible authorities ("RAs") claim the protection of "the public". In reality, this "public" is neither unitary nor uniform, but diverse and divided. Protection of the public, therefore, means actively seeking to develop cultural competence amongst practitioners to ensure their culturally safe practice. The minimum standard expected of a regulatory framework in Aotearoa New Zealand would be that it takes its public duty seriously by recognising and upholding Te Tiriti o Waitangi | The Treaty of Waitangi ("the Treaty”) (see Morice \& Woodard, 2011), and by adhering to and living up to international cultural competence standards (Dyck \& Kearns, 1995). Some of the key components of cultural safety include:

- The integration of bicultural and multicultural content into everyday practice

- The recognition that knowledge is culturally constructed

- The need for equitable rather than inequitable practice

- The reduction of social prejudice

- An ability to critique institutional authority and power.

Openness, transparency, and good faith are crucial to the success of this enterprise. The requirement to develop "cultural competence" may lead to authentic consciousnessraising and significant cultural exchange, or it may merely generate a series of tick-box rituals of compliance (Ramsden \& Spoonley, 1993).

The five page document outlining the NZPB's (2011) approach to cultural competency illustrates some of the strengths of a regulatory approach, as the preamble to its statement on cultural competence concludes:

Acquiring cultural competence is an accumulative process that occurs over many years, and many contexts. Practitioners are not expected to be competent in all the areas contained below. However, practitioners should take all reasonable steps to meet the diverse needs of their client population and these competencies are proposed to set standards and enhance the practice of psychology with diverse groups. (p.1)

The NZPB's statement begins by acknowledging our bicultural context and the centrality of the Treaty: 
The Government affirms that Mãori as tangata whenua hold a unique place in our country, and that Te Tiriti o Waitangi/The Treaty of Waitangi is the nation's founding document. To secure the Treaty's place within the health sector is fundamental to the improvement of Māori health ... a working knowledge of the Treaty is recognised as a fundamental basis of cultural competent practice. In the health sector, key Treaty principles for involving Māori include partnership, participation and protection. The Board is committed to ensuring these principles are acknowledged and actioned ... and the importance of respecting the "dignity of people and peoples". (p. 2)

It defines cultural safety:

Cultural safety relates to the experience of the recipient of psychological services and extends beyond cultural awareness and cultural sensitivity. It provides consumers of psychological services with the power to comment on practices and contribute to the achievement of positive outcomes and experiences. It also enables them to participate in changing any negatively perceived or experienced service. (p. 2)

... and its implications for the practitioner:

The psychologist delivering the psychological service will have undertaken a process of reflection on his or her own cultural identity and will recognise the cultural origins, assumptions and limitations of certain forms of psychological practice within some cultural contexts. Unsafe cultural practice comprises any action which diminishes, demeans, or disempowers the cultural identity and wellbeing of an individual, family or group. (p.3)

\section{It defines cultural competence as:}

having the awareness, knowledge, and skills, necessary to perform a myriad of psychological tasks that recognises the diverse worldviews and practices of oneself and of clients from different backgrounds. Competence is focused on the understanding of self as a culture bearer; the historical, social and political influences on health ... and the development of relationships that engender trust and respect. Cultural competence includes an informed appreciation of the cultural basis of psychological theories, models and practices and a commitment to modify practice accordingly. (pp.3-4)

It is important to acknowledge the many strengths of this document, including:

1. Its commitment to transparency and good faith

2. Its acknowledgement of Te Tiriti | The Treaty as foundational and central to the development of partnership with Māori 
3. Its commitment to cultural safety as a significant step beyond cultural awareness and cultural sensitivity which clearly demonstrates practitioners' willingness to take responsibility for outcomes

4. Its simple, clear three-part structure of awareness, knowledge, and skills, as each of these contribute to culturally competent practice. Awareness includes self-awareness and self-understanding and explicitly addresses the dangers of culturally driven judgment and bias. Knowledge covers specific domains of understanding and includes social and political as well as psychological knowledge. Skills focus on practical, realworld abilities to assess, plan, and deliver culturally safe services.

As regulatory documents go, this is a good one. But the devil is in the detail. How do we integrate awareness, knowledge and skill to ensure culturally safe practice? Awareness, knowledge and skills must function together if they are to generate culturally competent performances and make a positive difference. How do we measure cultural competence? What principles should we use to organise cultural supervision and how ought it be evaluated? How would we know if our work with a Māori client was generating the right kind of clinical and cultural outcome? How would we know if we were respecting the dignity of peoples as well as persons? Certain forms of racism and social prejudice are overt. Some are intentional. However, many forms of racism and social prejudice are deeply embedded in the dominant white and Western unconscious, out of sight and out of mind (McIntosh,1990; Ramsden \& Spoonley,1993). How would we go about monitoring these? If the primary benchmark which is attached to meeting these standards is the practitioner's own self-report that he or she is "working on" becoming culturally competent, is this sufficient? In practice, practitioner self-reports are accepted at face value so long as clients appear satisfied and don't complain., but then again, if the client does make a complaint on cultural grounds, the practitioner is often implicitly assumed to be at fault: guilty until proven innocent. While this may be a victory for holding professionals accountable, its tends to violate the principle of natural justice and veer reactively towards political correctness rather than accurately reflecting the need for the responsible professionals to set and maintain their own high standards.

\section{The Role of Cultural Supervision}

Cultural supervision not only develops and hones specific forms of awareness, knowledge and skills, but also helps the culturally competent psychotherapy practitioner to integrate his or her awareness, knowledge and skills and apply these with respect to self, other, the relationship between self and other, colleagues, the profession, the local community, institutions, the State and other sources of power and authority, society as a whole, and the wider commonwealth of life. Cultural supervision operates at multiple levels on the continuum from microsocial to macrosocial understanding (McKinney, 2006; Fay, 2008, 2011).

At the microsocial or microcultural level which foregrounds and brings into focus personal one-to-one encounters between practitioner and client, cultural supervision closely resembles clinical supervision. Cultural assessment, cultural formulation, 
cultural treatment planning and cultural intervention are necessary and critical dimensions of clinical work. This remains so even when the cultural similarity between practitioner and client locates this part of the work in the background rather than the foreground of consciousness. A robust psychotherapy should be able to address the ongoing intercultural encounter between therapist and client, an important dimension of the intimate relationship that will repay close attention. Specific domains of interest in cultural supervision at this microsocial/microcultural level might include:

- The therapist's cultural self-understanding

- Cultural influences on the formation and function of a client's personal identity

- Cultural influences on a client's personal healthcare preferences

- Cultural influences on the therapy relationship, including culturally determined power influences and imbalances

- The need for cultural consultation and/or referral.

At the mid-social level of group membership and group identity, the analogy to family and group therapy is useful. Cultural supervision explores the wider social and cultural context of the client's past and present, the whariki (woven mat) of kinship, the nexus of familial and social relationships whose weave binds us together, and the korowai (cloak) the lineage that connects us to ancestors and forbearers. These connections ground and contextualise the social and cultural context of the therapy project itself, and bring our lives to the fore as well, not just as professionals but as people. Specific domains of interest in cultural supervision at this mid-social level might include:

- Family representations of cultural heritage

- Family minority status

- Family history of immigration, migration, displacement and re-location

- Cultural influences on professional theory, method and practice

- Cultural influences on assessment and research paradigms

- Challenges to inequity, inequality, discrimination and bias.

Finally, at the macrosocial and macrocultural level of analysis, we can develop our awareness and understanding of the struggles of peoples to grow more fully into themselves; to become enlightened and empowered; to co-determine their own destiny; and to become able to make good decisions and healthy life choices. Specific domains of interest in cultural supervision at this level might include:

- Te Tiriti o Waitangi

- Te Reo Māori and Tikanga Māori

- Biculturalism

- Multiculturalism

- Politics and human rights

- Holistic approaches to health and illness

- Cultural ecology and the commonwealth of life. 
To conclude, we have sought to make clear that cultural supervision is not just for "them". The benefits of cultural supervision do not depend on how many Māori clients you are seeing or whether you see Māori clients at all. Cultural supervision may be an ethical and professional requirement, but it can also be much more than that: a unique and valuable opportunity to learn and grow personally and professionally. Cultural supervision helps to bring all forms of psychotherapy more fully into the $21^{\text {st }}$ century, into a complex, multi-ethnic, multi-cultural, and increasingly intimate and interdependent world. Peoples as well as people can and do make the therapeutic journey from engagement to enlightenment to empowerment (Durie, 2009), and culturally competent psychotherapy practice is a vital part of this larger human project of emancipation.

\section{References}

Dalal, F. (2002). Race, colour and the processes of racialization: New perspectives from group analysis, psychoanalysis and sociology. London, UK: Karnac Books.

Durie, M. (2001, 22 $2^{\text {nd }}$ November). Cultural competence and medical practice in New Zealand. Paper presented at the Australian and New Zealand Boards and Council Conference, Wellington, Aotearoa New Zealand.

Durie, M. (1985). A Māori perspective of health. Social Science Medicine, 20(5), 483-486.

Durie, M. (2009, $19^{\text {th }}$ August). Indigenous ethics and allied health practice. A presentation to Nga Pou Mana - Māori Allied Health Professions Hui-a-Tau, Levin, Aotearoa New Zealand.

Dyck, I., \& Kearns, R. (1995). Transforming the relations of research: towards culturally safe geographies of health and healing. Health \& Place, 1(3), 137-147.

Fay, J. (2007, $14^{\text {th }}$ May). The wisdom of psychotherapy. A presentation to the Northern Region Branch of the New Zealand Association of Psychotherapists, Auckland, Aotearoa New Zealand.

Fay, J. (2008, $11^{\text {th }}$ October). Psychotherapy invites the dream, locates the pain, imagines the good outcome and holds the hope that if I can change, so can the world. Presentation to the $4^{\text {th }}$ World Congress of Psychotherapy, Beijing, China.

Fay, J. (2011, 23 ${ }^{\text {rd }}$ August). Psychotherapy for the human family. An invited keynote address at the $5^{\text {th }}$ World Congress for Psychotherapy, Sydney, Australia.

Fay, J. (2012). New directions in international psychotherapy. Psychotherapy and Politics International, $10(1), 17-25$.

Fuertes, J. N. (2004). Supervision in bilingual counseling: Service delivery, training, and research considerations. Journal of Multicultural Counseling and Development, 32(2), 84-94.

Gone, J. P. (2010). Psychotherapy and traditional healing for American Indians: Exploring the prospects for therapeutic integration. The Counseling Psychologist, 38(2), 166-235.

Ivey, A. E., Ivey, M. B., \& Simek-Morgan, L. (1993). Counseling and psychotherapy: A multicultural perspective. Needham Heights, MA: Allen \& Bacon.

Jones, A. (1999). The limits of cross-cultural dialogue: Pedagogy, desire, and absolution in the classroom. Educational Theory, 49(3), 299-316.

McIntosh, P. (1990). White privilege: Unpacking the invisible knapsack. Independent School, 49(2), 31-36.

McKinney, K. J. (2006). A Māori medical model of cultural supervision. New Zealand Family 
Physician, 33(5), 301-304.

Middleton, S. (Ed.). Women in education in Aotearoa. Wellington, Aotearoa New Zealand: Allen Unwin/Port Nicholson Press.

Morice, M. ( 2003). Towards a Māori psychotherapy: The therapeutic relationship and Māori concepts of relationship. A systematic literature review with case illustrations (Master's thesis, Auckland University of Technology, Auckland, Aotearoa New Zealand).

Morice, M. (2006, April). Psychotherapy through the lens of the Treaty. Panel presentation at the New Zealand Association of Psychotherapists Annual Conference. NZAP Newsletter, pp. 29-34.

Morice, M. (2009, November). Te Ao Māori ethical values and principles applicable to the practice of psychotherapy. In J. Fay (Ed.), D-day for psychotherapy registration (pp. 59-62). NZAP Newsletter, pp. 47-65.

Morice, M. (2012, $5^{\text {th }}$ April). Māori concepts of relationship: Ethical and clinical guidelines. Presentation at the Inaugural Hui "Continuing the Dream - Haere tonu Nga Moemoe", Whaiora Marae, Auckland, Aotearoa New Zealand.

Morice, M., \& Fay, J. (2012, September). Cultural competencies and cultural supervision. NZAP Newsletter, pp. 22-35

Morice, M., \& Hall, A. (2011, $8^{\text {th }}$ March). Cross-cultural engagement in therapeutic practice. Workshop at Whaiora Marae, Auckland, Aotearoa New Zealand.

Morice, M., \& Woodard, M. (2011). Māori psychotherapy and the requirement to register under the Health Practitioners Competency Assurance Act 2003. In K. Tudor (Ed.), The turning tide: Pluralism and partnership in psychotherapy in Aotearoa New Zealand (pp. 69-76). Auckland, Aotearoa New Zealand: LC Publications.

New Zealand Psychologists Board (2011). Cultural competencies. Retrieved $30^{\text {th }}$ June, 2013, from www.psychologistsboard.org.nz/resources/resources2.

Pere, P. (1988). Te Wheke: Whaia te maramatanga me te aroha. In S. Middleton (Ed.), Women and education in Aotearoa, Vol 1 (pp. 6-19). Wellington, Aotearoa New Zealand: Port Nicholson Press.

Psychotherapists Board of Aotearoa New Zealand. (2013). Gazetted documents - Scopes of practice and fees: Conditions on scope of practice: Competence to practice in the New Zealand context. Retrieved $3 \mathrm{O}^{\text {th }}$ June, 2013, from www.pbanz.org.nz/index.php?GazettedDocuments

Ramsden, I., \& Spoonley, P. (1993). The cultural safety debate in nursing education in Aotearoa. New Zealand Annual Review of Education, 3, 161-174.

Rich, P. (1993). The form, function, and content of clinical supervision. The Clinical Supervisor, 11(1), 137-178. DOI: 10.1300/Joo1v11no1_10

Smith, L. T. (1999). Decolonizing methodologies: Research and indigenous peoples. London, UK: Zed Books.

Tervalon, M., \& Murray-Garcia, J. (1998). Cultural humility versus cultural competence: a critical distinction in defining physician training outcomes in multicultural education. Journal of Health Care for the Poor and Underserved, 9(2), 117-125.

Vera, E. M., \& Speight, S. L. (2003). Multicultural competence, social justice, and counseling psychology: Expanding our roles. The Counseling Psychologist, 31(3), 253-272.

Walker, R. (1990). Ka whawhai tonu matou - Struggle without end. Auckland, Aotearoa New 
Zealand: Penguin.

Walker, S., Eketone, A., \& Gibbs, A. (2006). An exploration of kaupapa Māori research, its principles, processes and applications. International Journal of Social Research Methodology, 9(4), 331-344.

Wear, D. (2003). Insurgent multiculturalism: rethinking how and why we teach culture in medical education. Academic Medicine, $78(6)$, 549-554.

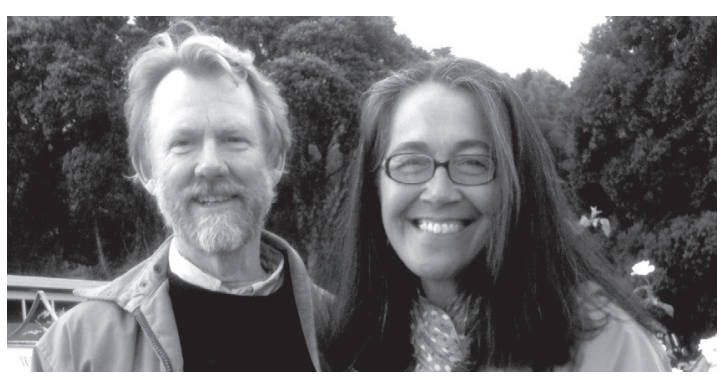

Margaret Poutu Morice, MHSc (First Class Hons.), MNZAC, MNZAP is a Founding Member of Nga Ao E Rua, a Founding Member and Runanga Member of Waka Oranga, and a Member of Nga Pou Mana (Māori Allied Health Professionals). She trained as a psychotherapist and works as a kaiwhakaruruhau wahine Māori social and mental health practitioner, with many years' experience working in designated Māori positions within "mainstream" public and private organisations. Her practice includes cultural supervision with professional groups who are committed to understanding and addressing the chasm of inequity which exists for Māori in accessing social and health services. She has a lifetime experience of living biculturally within a monocultural Western society. Contact details: margaretmorice@xtra.co.nz .

Jonathan Fay is a clinical psychologist with 35 years' experience practicing, teaching and supervising psychotherapy in the USA and Aotearoa New Zealand. Jonathan has always been active in the psychotherapy community in Aotearoa New Zealand, serving on the Executive Council of the NZAP for 12 years and teaching in the AUT University's psychotherapy training programme in Auckland for 13 years. He has a practice in Hawke's Bay, and maintains a small private practice offering therapy, supervision, and consultancy in Auckland. Contact details: jonathan.fay@xtra.co.nz .

Margaret and Jonathan are married, have three adult children, and divide their professional lives between Onga Onga, Hawke's Bay, and Auckland. 